\title{
Editorial
}

\section{Digital technology, population health, and health equity}

Journal of Public Health Policy (20I6) 37, SI $45-S_{\text {I }} 53$.

doi:IO.IO57/s4I 27I-OI 6-004 I-O

\section{Introduction}

Notwithstanding major progress during the Millennium Development Goal (MDG) era, the global challenges of health inequalities, complex disease burdens, and weak health systems remain. ${ }^{\mathrm{I}, 2}$ In the past decade, several authors have pointed to the potential and power of digital technology (DT) to address some of these challenges. ${ }^{3-5}$ The health care system is replete with examples about the use and impact of digital technologies on human health, ranging from magnetic resonance imaging, personal electronic health cards, through to nanotechnology and genomics. The focus of many of the DT applications, however, tends to be on individual health and personalized medicine, on patients (once the person needs a medical intervention or health care service), about how digital technologies are revolutionizing the delivery of diagnostic and treatment services, and to help those within the health care system make better clinical and cost decisions. ${ }^{6-9}$

In contrast, there was until recently a dearth of information about the extent to which and how digital technologies have been used within the realm of public health, as a means of preventing disease and injury and promoting/protecting health, and the benefit of such technologies in terms of population gains in health and health equity. In early 20I4, the World Federation of Public Health Associations (WFPHAs) conducted a literature review, and found that none of the articles on DT assessed the impact of its use on population health outcomes, nor did they take into consideration the impact of the social determinants of health on the uptake, use, and effect of DT on human health, nor on health equity. The WFPHA's interest in the use of DT in public health and its potential impact on human health was influenced by the work of its 
member organizations, the revision and preparation of the WFPHA's strategic plan in 2013 , and the intention to use information, communication technologies (ICT) to improve its own advocacy effectiveness, and knowledge about several innovative applications of DT within the health sector. ${ }^{4,5, \text { IO, II }}$

This JPHP Supplement focuses on the DT initiative of the WFPHA. The purpose of the initiative is twofold: first, to increase knowledge about and use of DT among frontline health workers and general population for population health and health equity gains, and second, to encourage the use of DT, when appropriate, to contribute to improvement in population health (disease $\&$ injury prevention, health promotion, health protection) and to address issues of health equity.

The Supplement brings together seven scholarly articles that explore the theme of use and impact of DT on human health and health equity within different contexts.

\section{Approach and Process}

In late 20I4, the WFPHA obtained funding from the Aetna Foundation for three interlinked components: a themed session at the I4th World Congress on Public Health held in Kolkata (India) in February 2015; the publication of a special section of the Journal of Public Health Policy; and a WFPHA discussion paper on the topic, to be released at the I 5th World Congress (Melbourne, Australia: 3-7 April, 2017).

We adopted several approaches to commission the articles: inviting pre-eminent scholars to compose articles; extending invitations to wellknown and highly respected international organizations to write about their experiences with digital technologies; to select potential authors from among the abstracts on the issue submitted as oral and poster presentations for the I 4 th World Congress and to consult with different groups and individuals familiar with the topic, seeking their advice as to who might be invited as a potential author.

Following some challenges with this approach, a small ad hoc WFPHA editorial committee adopted a more pro-active and selective approach.

- The Committee invited Dr. Alejandro Jadad, Founding Director, Centre for Global eHealth Innovations and Professor, Dalla Lana 
School of Public Health/University of Toronto, to write an article based on his future-looking presentation [(Mis)information and (mis)communication technologies?] delivered at the I4th World Congress on Public Health.

- In response to a call issued by the WFPHA to national PHAs to share their experiences in the use of DT, the Public Health Association of South Africa referred the call to the country's national health department, which was subsequently invited to prepare an article about its experiences in the application of DT to improve maternal and infant health outcomes.

- The Faculty of Health Sciences/American University in Beirut, that submitted a synopsis of its work with refugee and displaced populations, was invited to prepare an article on the use of DTs to improve health of populations affected by humanitarian crises.

- A group of researchers from Latin America, identified through the IDRC's SEARCH initiative, was also commissioned to examine the use of DT in reproductive health services in the Latin America/ Caribbean region.

- The Aetna Foundation contributed an article about the results and lessons learned through a USA-based initiative funded through its grants program.

- Finally, upon learning in early 2016 about its intention to conduct a pan-Canadian survey to assess how digital technology including social media is being used to support action on the SDOH and health equity, we invited the National Collaborating Centre on the Social Determinants of Health in Canada to prepare an article for us.

For each paper, we selected peer reviewers to ensure that papers would be sound, relevant, and interesting to an international audience. The authors revised their articles between January and April 2016 following receipt of reviewers' comments. We edited the papers during April and May for quality assurance and to comply with JPHP guidelines.

\section{Themes and Focus of the Journal Supplement}

This special section on the relationship between DT and health/health equity is, to the best of our knowledge, a first attempt to examine the

(C) 2016 Macmillan Publishers Ltd. oI97-5897 Journal of Public Health Policy Vol. 37, S2, SI45-SI53 SI47 
issue from a public/population health perspective. Although the seven commissioned articles have their limitations and shortcomings, they do provide a snapshot about how DT is used in a variety of public health settings within differing contexts.

- Barron et al. report on an analysis of the metrics used to assess the effectiveness of an innovative mobile phone-based application in South Africa to improve health outcomes of pregnant and postpartum women and their infants by increasing access to and the quality of maternal-newborn health services. They discuss how DT empowers service users. Although the study did not assess the impact of the technology on health outcomes, it did confirm greater use of maternal-neonatal services by women using the app. Technology also assisted health service personnel improve patient interaction and the quality of services provided. The authors found that the DT made a difference to the overall quality and use of primary health care services.

- Nigenda et al. present a systematic review of the use of DT for the prevention of sexually transmitted infections and the promotion of sexual and reproductive health services in the Latin America and Caribbean region. As they note, mobile phone coverage in most countries in this region exceeds 80 per cent and over 60 per cent have access to the internet. The Pan American Health Organization's promotion of DT for health has helped garner political support for its adoption in many countries.

- Mesmar and her associates at the American University in Beirut (Lebanon) examine the use and impact of DT among people caught up in and affected by humanitarian crises (HC), and how such technology helps responders better understand complex HC situations and the needs of affected communities, to facilitate response efforts, and to engage the affected populations in the response. They identify several technologies that have played an important role in improving the effectiveness of $\mathrm{HC}$ responses. Of note is the role played by Geographic Information Systems (GIS), which Mesmar et al. describe as a 'major game changer.' They also cite gaming software, real-time surveillance systems, social media, and the increasing availability of low-cost computer hardware and software.

- Graham and his associates at the Aetna Foundation describe its approach to grants-making and draw on the results and lessons they

SI48 (C) 2016 Macmillan Publishers Ltd. o197-5897 Journal of Public Health Policy Vol. 37, S2, SI45-SI53 
learned from several initiatives supported in the USA. The aim of the Foundation's program is to inspire healthier lifestyles and create healthier communities. The use of mobile phone applications in underserved areas helped create better understanding about healthier food choices, increased consumption of fresh fruits and vegetables, improved people's capacity to read and understand nutritional labeling, and increased the effectiveness of post-stroke rehabilitation.

- Chauvin, Perera, and Clarke explore the use of DT by national public health associations (PHA), its impact on their organizational and programmatic activities (including advocacy) and whether/how PHAs assess the impact of such technologies. PHAs use DT primarily as a means to communicate with their members and to disseminate information about best practices and policies to other stakeholders, government authorities, and to the general public. It tends to be restricted to websites, the use of mobile phone applications, social media (primarily Facebook and Twitter), blogs, online fora, and webinars. Only a few NGOs, mainly those located in higher-income, digitally advanced countries, have experience with more sophisticated DT usage. The assessment of DT impacts tends to focus on process and output metrics (for example, the 'uptake' of mobile applications, the number of hits on a PHA website). The evaluation of the potential impact of DT on population health outcomes and health equity remains missing from the picture.

- Ndumbe-Eyoh and Mazzucco report on the results of the panCanadian survey about how digital technology is being used to support action on the SDOH and health equity. The survey's findings indicate that public health workers use social media for knowledge translation, relationship building, and specific public health roles to advance health equity. Organizations in which they work could develop policies and provide training opportunities to enhance skills to enable a more substantive use of digital technologies to advance public health practice and to address health equity.

- Jadad asks us to adopt a new concept of health. The question is not how DT affects health; rather, how DT can be used to mobilize the assets at the disposal of individuals and communities to elevate the status for those who do not feel healthy while protecting those who already consider their health to be good. Can we shift from thinking about what causes disease and injury, to what causes health? It would require adopting the concept of resilient people and communities. 


\section{Issues relating to the use of DT for health gains}

A review of the articles, plus information drawn from several articles and reports published in recent months reveals a rich experience in the use of DT for health results from around the world. Perhaps the largest application of DT within the field of public health is happening within the areas of disease surveillance, population health surveillance, and emergency and pandemic response. Considerable effort has been made in recent years to create and promote apps and other DT-related tools in the area of health promotion, especially to aid lifestyle choices and behavior change. These are important advances and their impact on the capacity of health systems to respond and address conditions that affect human health cannot be overlooked or denied.

That being said, the literature, including the seven commissioned articles, identifies several challenges in the use of DT for health and health equity gains. Due to the lack of space in this special section of the JPHP, we can only list a few of them, but we believe these are the most important ones:

- Scalability, reproducibility, transferability, sustainability of digital technology interventions, especially in low- and middle-income countries;

- Incorporating the use of DT within population health approaches requires an understanding and acceptance that people come first and technology second. ${ }^{\text {IO }}$ Getting swept up in hype about technology and ignoring the community's needs and perspectives about how the factors that affect human health could and should be addressed.

- Few initiatives are founded on a user-centered design approach to DT, as the industry pushes digital technologies for profit;

- Focus on personalized (not population) medicine/health;

- Resource constraints (financial, human resources, organizational capacity);

- Unequal access to and/or digital literacy/exclusion. Who actually benefits?; and

- Ethics \& privacy. 
Perhaps the most significant challenge is how difficult it will be to demonstrate impact and attribute positive outcomes for population health and health equity directly to the use of DT. The Lancet report on global health technologies reported that evidence of effectiveness gleaned from the nine randomized controlled trials for mHealth in lowincome countries cited was "weak." ${ }^{\text {I2 }}$ Most studies of effectiveness tend to focus on the impact of DT on health worker performance, quality of service, and health service efficiency. The launch of the WHO's mHealth Assessment and Planning for Scale (MAPS) Toolkit ${ }^{\mathrm{I} 3}$ and the mHealth Evaluation, Reporting and Assessment (mERA) checklist ${ }^{\mathrm{I}}$ are excellent starting points. But more needs to be done to put into place the methodologies and the metrics to assess the impact of DT on population health and health equity. Otherwise, we focus on the means rather than on the desired collective global end.

\section{Concluding Remarks}

The use of digital technologies is reshaping our health care systems and prompting us to rethink how we extend life and improve health. We have only begun to scratch the surface. "The Internet of Things," artificial intelligence, robotics (including drone technology, ${ }_{3} \mathrm{D}$-printing), have the potential to transform not only healthcare, but the way we live our lives. ${ }^{\mathrm{I} 5}$ The UN 2030 Agenda for Sustainable Development recognizes the potential impact of digital technologies and calls for investment in and access to them as a means to support the SDG's implementation and achievement. ${ }^{\mathrm{I} 6}$ There is a huge potential for DT within public health, with a high pay-off in terms of health and health equity.

What is evident to the authors of this overview article is the urgent need for the global public health community, and especially national public health associations and the WFPHA, to show leadership and contribute to the discussion on the place of DT for population health and health equity gains. We can no longer sit on the sidelines. If we are to represent the civil society voice of public health in our respective countries and internationally, then we need to define a public health approach to the use of DT, and help address the challenges related to its use, especially when it comes to assessing the impact of DT on health and health equity.

(C) 2016 Macmillan Publishers Ltd. oI97-5897 Journal of Public Health Policy Vol. 37, S2, SI45-SI53 SI 
We hope this series of articles will generate discussion within the public health community. We also hope it will serve to strengthen links between public health associations, the WFPHA, national governments, NGOs, and other organizations and institutions involved in the development and deployment of DTs.

\section{Acknowledgments}

The WFPHA is grateful to the Aetna Foundation for funding this JPHP Supplement. We are indebted to numerous individuals, without whose assistance, the publication would not have been possible: (a) Professors Phyllis Freeman and Anthony Robbins, the editors of the Journal of Public Health Policy, for their incredible support, encouragement, and insightful advice over the past several months; (b) our reviewers from Canada, the United States, South Africa, the United Kingdom, and Mexico whose insightful comments helped to strengthen the commentaries and papers a great deal; and, (c) the authors of the articles, who invested considerable time and effort in preparing them to the JPHP's standards and for sharing their thoughts, opinions, experiences, and research findings with us.

\section{References}

I. World Health Organization. (2016) World health statistics 2016: Monitoring health for the sustainable development goals. Geneva: WHO.

2. UNDP. (2015) Human development report 2015 - work for human development. New York: UNDP.

3. Tucker, S. (2016) Welcome to the world of mHealth. mHealth I(I). doi:I0.3978/j.issn.23069740.201 5.02.01.

4. Howitt, P., Darzi, A., Yang, G.-Z., Ashrafian, H., Atun, R. and Barlow, J., et al (2012) Technologies for global health. Lancet 380(9840): 507-535. doi:Io.IOI 6/So I 40-6736(I2)6I I 27-I.

5. Sinha, C. and Garro-Strauss, D. (2013) Research on eHealth across health systems: Contributions to strengthen a field. In: L. Elder, H. Emdon, R. Fuchs and B. Petrazzini (eds.) Connecting ICTs to Development: The IDRC Experience New York: Institution: I6I-I95.

6. Weil, A. (2015) How valuable is information? Health Affairs 34(3): 366. doi:IO.I377/hlthaff. 2015.0139.

7. Wyber, R., Vaillancourt, S., Perry, W., Mannava, P., Folaranmi, T. and Celi, L.A. (2015) Big data in global health: Improving health in low- and middle-income countries. Bulletin of the World Health Organization 93: 203-208. doi:I0.247I/BLT.I4.I39022.

8. Buell, J.M. (20I I) The digital medicine revolution in healthcare. Healthcare Executive: 29-34.

SI 52 (C) 2016 Macmillan Publishers Ltd. OI97-5897 Journal of Public Health Policy Vol. 37, S2, SI 45 -SI 53 
9. Medicine Goes Digital. (2009) The Economist. http://www.economist.com/surveys/displaystory. cfm?story_id=I3437990.

Io. Barclay, G., Sabina, A. and Graham, G. (2014) Editorial: Population health and technology: Placing people first. American Journal of Public Health I04(I 2): 2246-2247. doi:10.2105/ AJPH.20I4.302334.

II. World Health Organization (WHO). (20II) mHealth: New horizons for health through mobile technologies: based on the findings of the second survey on eHealth. Geneva: WHO. Available from, http://www.who.int/goe/publications/goe_mhealth_web.pdf.

I2. Howitt, P., Darzi, A., Yang, G.-Z., Ashrafian, H., Atun, R. and Barlow, J., et al (20I 2). Technologies for global health. Lancet $380(9840$ ): 507-535. doi:IO.IOI 6/SOI 4O-6736(I 2)6 I I 27-I.

I3. World Health Organization. (20I5) Launch of mHealth toolkit to help innovators scale up projects for reproductive, maternal, newborn, child and adolescent health. Geneva: WHO. Available from, http://www.who.int/reproductivehealth/topics/mhealth/maps-toolkit/en/.

I4. Agarwal, S., LeFevre, A.E., Lee, J., L'Engle, K., Mehl, G. and Sinha, C., et al (2016) Guidelines for reporting of health interventions using mobile phones: Mobile health (mHealth) evidence reporting and assessment (mERA) checklist. BMJ 352. doi:IO.I I36/bmj.iII 74 .

I 5. Cashin-Garbutt, A. (20I6) Could the Internet of things transform healthcare? London, UK: News-Medical Life Sciences and Medical, AZoNetwork UK Ltd. Available from, http://www. news-medical.net/news/201602 I 5/Could-the-Internet-of-Things-transform-healthcare.aspx.

I6. Ericsson.com. (2015) How information and communications technology can achieve the Sustainable Development Goals. New York: Ericsson in collaboration with Earth Institute at Columbia University. Available from, https://www.ericsson.com/res/docs/2015/ict-and-sdginterim-report.pdf.

James Chauvin
Past-President, World Federation of Public Health Associations, Gatineau,
Canada

Laetitia Rispel

Chair/WFPHA Global Health Equity Working Group, Johannesburg, South Africa 